\title{
ARTIVISMO FEMINISTA Y FLASHMOB: LENGUAJE CORPORAL EN EL MUNDO ORIENTAL
}

\section{Teresa Colomina-Molina}

\section{Resumen}

Las redes sociales permiten compartir contenido diverso y mantener una interconectividad entre usuarios a nivel global. Este estudio analiza las formas de expresión y representación del fenómeno Flashmob realizado por mujeres en el continente asiático, a través de la red social Instagram. Se pretende averiguar si existe un nexo con el movimiento artivismo feminista. El análisis de los datos se hizo a partir de una metodología basada en un análisis cuantitativo y descriptivo de contenido. Teniendo en cuenta las diferentes características que se han señalado en el estudio - género, ubicación, música e indumentaria utilizada - se puede apreciar que el Flashmob favorece el empoderamiento de la mujer en la India y el sudeste asiático.

Palabras clave: Asia, artivismo, feminismo, Flashmob, Internet.

\section{Resumo}

Artivismo feminista e Flashmob: linguagem corporal no mundo oriental

As redes sociais permitem partilhar diversos conteúdos e manter a interconectividade entre utilizadores a nível mundial. Este estudo analisa as formas de expressão e representação do fenómeno Flashmob realizado por mulheres no continente asiático, através da rede social Instagram. O objectivo é descobrir se existe uma ligação com o movimento do artivismo feminista. A análise de dados foi feita a partir de uma metodologia baseada na análise quantitativa e descritiva de conteúdo. Tendo em conta as diferentes características que são apontadas no estudo - género, localização, música e vestuário utilizados -, pode ver-se que o Flashmob favorece o empoderamento das mulheres na Índia e no Sudeste Asiático.

Palavras-chave: Ásia, artivismo, feminismo, Flashmob, Internet.

Departamento de Expresión Plástica, Musical y Dinámica, Facultad de Educación, Universidad de Murcia, Murcia, España.

Dirección postal: Facultad de Educación de la Universidad de Murcia, Campus de Espinardo, 30100 Murcia, España.

Correo electrónico: colomina@um.es 


\begin{abstract}
Feminist Artivism and Flashmob: Body Language in the Eastern World

Social networks make it possible to share diverse content and maintain interconnectivity between users at a global level. This study analyses the forms of expression and representation of the Flashmob phenomenon carried out by women on the Asian continent through the social network Instagram. The aim is to find out if there is a link with the feminist artivist movement. The data analysis was made using a methodology based on a quantitative and descriptive content analysis. Taking into account the different characteristics that are pointed out in the study - gender, location, music and clothing used - it can be seen that the Flashmob favours the empowerment of women in India and Southeast Asia.
\end{abstract}

Keywords: Asia, artivism, feminism, flashmob, Internet.

\title{
Introducción
}

Desde la mitad de los años 1980 y tras el fin de la Guerra Fría, el mundo, heredero de la corriente alternativa que se conformó en Mayo del 1968, después de una serie de protestas espontáneas, comenzó a desplegar una corriente de progreso en temáticas tan dispares como los derechos humanos, el feminismo, la ecología, la libertad sexual o la búsqueda de la igualdad económica y social entre los seres humanos (Álvarez 2018). A la vez coexistían junto a un vertiginoso avance científico, tecnológico y financiero. Todos estos ítems son diferentes caras de una misma moneda llamada globalización.

Esta rápida comunicación ha quedado validada por el vasto desarrollo de la era de Internet o lo que podemos llamar el quinto poder: «La web 2.0» (Dinucci 1999). Ya que el cuarto poder, también conocido como los mass media, según Chomsky (1997), ha sucumbido a las necesidades de los políticos y no a los de la gente, ya que el fundamento en una democracia real es que los ciudadanos puedan expresar sus ideas libremente. Así mismo, Ramonet (2004) dice que los medios de comunicación - TV, radio y prensa escrita - han sido fagocitados por grupos mediáticos que les impiden realizar la función de representar a las personas si sus intereses se ven amenazados. Por esta razón, creemos que la ciudadanía ha encontrado en Internet el medio ideal para conformar el contrapoder que les preserve del abuso institucional, empresarial o gubernamental, permitiendo la inmediatez del flujo comunicativo, siendo la web el reflejo, el doble virtual de todo lo que acontece en el mundo, la herramienta explícita de las diversas expresiones artísticas que son muestra de las inquietudes de la sociedad del siglo XXI.

Por todo lo descrito, se podría llegar a pensar que la globalización es un fenómeno que se caracteriza por la interconectividad de las personas o sus bienes alrededor del planeta, favoreciendo la aparición de distintos movimientos activistas que fusionan la réplica social con medios informáticos, tecnológicos y artísticos, como el Teatro, la Danza, Performance o el Flashmob, que destaca por su fácil e instantánea 
retrasmisión. Y es que Internet ha eliminado las fronteras territoriales en el ámbito virtual generando nuevas redes comunicativas entre grupos de personas sin importar su situación geográfica. Por tanto, en este estudio se va a investigar la construcción del artivismo feminista y el Flashmob en las coordenadas geográficas de oriente.

Para entender la esencia de lo que es el artivismo, se podría usar la cita de Gordimer (1984, 7), en la que se refiere al escritor Albert Camus cuando dice que «aceptó su condición de que la mayor responsabilidad es hacia la sociedad y no al arte». Los artivistas utilizan el arte como instrumento de protesta social a través de diversas disciplinas, pero teniendo en común que se dan en la calle, que es el paroxismo del concepto de espacio público. Por tanto podemos entender que el artivismo tiene un componente agitador o propagandístico, herencia del Agitprop de la Revolución Rusa, entendiendo que «[e]l arte agitprop desempeñó un papel importante en la Revolución, en particular en las celebraciones públicas, donde se le prestó especial atención» (Korobina 2015, 86).

Esta idea de unificar propaganda política y arte se expandió rápidamente por varios continentes. En China, por ejemplo, casi una década antes del estallido de la Segunda Guerra Mundial, con el objeto de concienciar a la población para resistir ante la ofensiva japonesa, el teatro abandona los escenarios para que los campesinos tomen conciencia del problema al que su nación se enfrenta (Tang 2016). El modelo de acercar el teatro al pueblo llevándolo a la calle ocurre unas décadas después en Brasil, en los años 1960, como propuesta de Augusto Boal (1931-2009) para concienciar al pueblo y ayudarle a cambiar su situación. Esta situación de cambio nos aboca a presagiar que «la esencia del teatro es popular. Siempre ha habido teatro popular porque siempre ha habido pueblo. Por tanto, en la visión de Boal, el teatro debería ser popular y postular como fin el cambio social» (Chesney-Lawrence 2013, 34).

Según Boal $(1989,59)$ «la poética del Teatro de los oprimidos es en esencia la poética de la liberación: el espectador ya no delega poderes en los personajes ni para que piensen ni para que actúen en su lugar». Es el propio espectador el que encarna al personaje, el que emigra a la escena y se convierte en actor, en parte activa de la función. De esta manera, vive la experiencia desde dentro y le abre el camino para motivar cambiar su entorno y su realidad social.

Durante el siglo XX ha habido corrientes artísticas que han manifestado, como Beuys (1983), que todo ser humano es un artista. El teatro, por su particularidad de usar la palabra y la acción es, además de un arte, una herramienta muy poderosa de comunicación. La simpleza de sus necesidades básicas para existir lo hace permisible y alcanzable a todo el mundo. En este sentido, Brook $(1987,5)$ considera que «puede tomar cualquier espacio vacío y llamarlo un escenario desnudo. Un hombre camina por este espacio vacío mientras otro le observa, y esto es todo lo que se necesita para realizar un acto teatral». Sin embargo, en el imaginario colectivo se relaciona teatro con escenario, telones, focos, patio de butacas, en definitiva, un teatro a la italiana. Esto para Salaün (2001) es herencia del teatro burgués y de la aristocracia, que declina los cambios estéticos promulgados por Wagner 
(1813-1883), Massenet (1842-1912) o Debussy (1862-1918) y aspira a ser representado para perpetuar su preponderancia y hacer acatar al pueblo qué es y qué no es arte. Por tanto, de ahí se podría extraer la reflexión de que las élites patriarcales, desde la antigua Grecia, son las que dictan qué es arte, qué es válido y qué no a su conveniencia para preservar ese distanciamiento social y clasista que también se produce en el ámbito artístico y afecta a todos, pero en especial a las mujeres.

Todo esto da lugar a la publicación, en 1932, del primer manifiesto del Teatro de la Crueldad de Antonin Artaud (1896-1948). Ello supone una escisión con el teatro naturalista y realista de las clases dominantes. Así, Artaud (1996) promulga sustituir el teatro basado en un texto por un teatro corporal y físico que nazca del gesto y que sea capaz de expresar. En definitiva, lo que busca es acabar con el teatro aristotélico de mimesis para dar cabida a un nuevo teatro capaz de explorar nuestra naturaleza humana a través del lenguaje corporal sustentado en el movimiento y en el gesto. Tomando en consideración las propuestas de Torrents y Castañer (2009), el cuerpo es un comunicador en sí mismo, por su carácter narrativo mediante códigos simbólicos. Así, y teniendo en cuenta la comunicación a través del cuerpo, los postulados de Artaud podrían ser uno de los referentes de la performance (Pavis 2008). La danza, junto al teatro, ha contribuido en la performance, el happening y en la comunicación mediante la práctica de la expresión corporal.

En la misma línea de avance y según los antecedentes expuestos, también se podría considerar que la performance y el happening dan paso en el siglo XXI a lo que hoy día denominamos Flashmob, es decir, acción artística y comunicativa llevada a cabo mediante el avance de la tecnología y las redes sociales (Marcillas Piquer 2013). Otra cuestión a mencionar es el espacio donde se desarrollan estas acciones, ya que, como indica Lepecki (2011), toda intervención de caracter performativo descoreografia el escenario y se amplifica en el espacio común, pues la ciudad en sí misma se rige por unas coreopolíticas que los cuerpos tienen la oportunidad de apropiarse y transformar.

\section{Flashmobs}

Redes sociales como Facebook, Twitter, Instagram o YouTube han permitido generar contenidos de toda índole, entre ellos los Flashmobs, que pueden ser compartidos de forma inmediata por otros usuarios. Esta característica de la inmediatez es además una peculiaridad intrínseca de los primeros Flashmobs. Para Chauca (2015), el Flashmob comparte semejanzas con el movimiento Fluxus por su noción renovada del arte, la falta de pretensiones, la incursión del arte en lo cotidiano o con la fusión de arte y vida del situacionismo, movimiento que, según FernándezQuesada (2000), a su vez plantea el término «psicogeografía» para estudiar la interacción entre entorno e individuo. 
Para Gore (2010), los Flashmobs surgieron en el año 2003 con la denominada «Love rug», cuando un grupo de «Hipsters» (Marcillas Piquer 2013), desconocidos entre ellos, se reunió en el centro comercial de Macy's, en Nueva York, en torno a una alfombra roja de 10.000 dólares durante unos minutos y se dispersaron después ante la perplejidad del empleado. Se habían organizado mediante Internet y el uso del correo electrónico. Esta acción supuso, inconscientemente para los implicados, una especie de broma o juego que conseguía acaparar la atención del espectador y que se expandiría por vía telemática a las grandes urbes del planeta. La elección de este producto no fue realizada al azar. Este tipo de alfombra se hizo famosa en los años 1970 por su eslogan publicitario The Love Rug strokes your bodies as you make love (La alfombra del amor acaricia vuestros cuerpos mientras haces el amor). En el cuerpo del propio anuncio se explica que la alfombra «[is] almost like having another lover there with the two of you» [Es casi como tener otro amante ahí con vosotros dos], lo que supuso un guiño a la liberación sexual comenzada a finales de la década de los 1960.

En opinión de Molnár (2014), existen varios tipos bien diferenciados de Flashmob. El primero de ellos es el flashmob atomizado. Según el diccionario de Oxford, atomizar significa dividir algo en pequeñas unidades. Por tanto, entendemos que un grupo de personas que va a realizar una acción está compuesto por individuos diferenciados que no se conocen entre ellos. $Y$ el autor explica que, para los puristas, es la forma originaria de realizar correctamente una Flashmob, donde el emplazamiento de ejecución son tiendas o espacios ubicados dentro de centros comerciales. La clave de esta catalogación es que el conjunto de personas que asisten a realizar la Flashmob no se conozcan ni interactúen entre ellos. Otro ejemplo para comprender el término ocurre cuando los integrantes acuden a bailar o escuchar una canción que puede ser la misma o diferente en sus smartphones y el baile no está coreografiado.

El segundo tipo es el flashmob interactivo, donde los integrantes interactúan entre sí. Existen unas reglas del juego que todos los participantes conocen, ya sea una pelea de almohadas o la existencia de un líder al que todos siguen e imitan. Estos Flashmob no tienen un carácter político, pero son un llamamiento para el uso y disfrute de los espacios públicos que cada vez más son arrebatados a la ciudadanía durante su tiempo de ocio con la premisa de consumir para poder disfrutar de estos espacios. Por tanto, existe un carácter legitimador en este tipo de acciones, ya sean artísticas o políticas, de reivindicar la tenencia de lugares para la comunicación y expresión, diferenciando espacios gratuitos de los de pago. Esto presenta una democratización de la participación, ya que, por otro lado, precisamente las grandes corporaciones se valen de alquilar partes del espacio común para publicitar sus productos, calando con mayor fuerza en la ciudadanía.

El tercer tipo es el flashmob performativo, en el cual se revive el espíritu de la performance artística y es concebido por una o varias personas con un objetivo artístico y unas pautas bien definidas. Podemos decir que tiene conexión con el land art, 
movimiento artístico que utiliza el entorno como material plástico (Sartoretti 2014), pero en vez de usar objetos que estimulan o se mimetizan con el entorno, son las propias personas las que se apropian del espacio y lo incentivan realizando algún tipo de acción, como cuando el puente peatonal de Brooklyn fue tomado por tres mil personas vestidas de blanco bajo la dirección de un grupo artístico llamado The Danger. Por tanto, a diferencia de las anteriores, estas tienen un marcado eje vertical o piramidal.

La cuarta tipología de los Flashmob engloba a los que tienen un alto contenido político y reivindicativo, que surgen de un movimiento llamado a su vez smart flashmob donde se realizan protestas de índole política, participando en una acción coordinada. No tienen por qué estar realizando un acto ilegal, pero sí tienen un alto contenido de demanda o queja por alguna reivindicación política que vaya en contra de los principios de los organizadores.

Finalmente, el quinto y último tipo de Flashmob es el que tiene fines publicitarios de alguna marca o entidad. Éste usa el reclamo de estas acciones para promocionar algún producto específico de forma que produzca un impacto original y atrayente entre los consumidores más jóvenes. Los consumidores, en este caso, pueden verse identificados por la marca, la música y toda la parafernalia que la acción elegida conlleva.

Por su parte, Chauca (2012) incide en que todas las categorías son conocidas por el nombre de Flashmobs sin que haya distinción real entre ellas, aunque las dividiría en dos grupos. Por un lado, están los Flashmobs de índole absurda, donde se realiza una acción por el hecho de hacer una acción con un componente lúdico (guerra de almohadas, ataque zombi y otros ejemplos similares). Por otro lado, se encuentra el llamado Smartmob, caracterizado por un tono intelectual y mucho más comprometido socialmente.

Un fenómeno y categorización espontánea que se ha observado al indagar sobre el Flashmob en la búsqueda en Internet es la forma de escribirlo. Por una parte, podemos encontrarlo escrito como «Flashmob» pero también es común encontrarlo escrito como «Flashmop». Esta particularidad, al principio, parecía deberse a una confusión por el uso del alfabeto latino por parte de personas no occidentales, pero no es así. La diferenciación se basa en que «Flashmop» es un término que deriva de «mop» en inglés («mopa, fregona») y es usado cuando existen protestas dentro del sector servicios (Prowse, Lopes \& Fells 2017). Y de este hecho también se hace eco cuando un grupo de trabajadores de los almacenes Tesco en Inglaterra entonaron canciones, mientras coreografiaban con sus utensilios de limpieza en señal de protesta por sus bajos salarios ${ }^{1}$. Por tanto, podemos dilucidar que se conoce por Flashmop cuando se realiza una protesta dentro del sector servi-

Rob Parsons, «“Flashmop” protest over Tesco cleaners' pay.» Evening Standard, 21 de junio del 2011. Disponible en https://www.standard.co.uk/news/flashmop-protest-over-tesco-cleaners-pay6413480.html [Consultado 27 de abril de 2020]. 
cios o cuando realizamos una acción que tiene que ver con prestar un servicio a la comunidad dentro de este ámbito, como puede ser limpiar, fregar, ordenar. Sin embargo, bajo esta etiqueta o hashtag se incluyen videos en las redes sociales que pertenecen a los Flashmobs.

\section{Artivismo, feminismo y expresiones del Flashmob en el mundo oriental}

Una vez aclarados los diferentes tipos de Flashmob, podemos apreciar la aparición de movimientos cómo el artivismo feminista que cada vez con más fuerza está consiguiendo logros a través del Flashmob y sus reivindicaciones.

¿Qué diferencia al artivista del activista? El artivismo difiere del activismo en cuanto que ornamenta con originalidad y dota de estética el discurso político. Lo adorna haciéndolo más cercano y más popular a la sociedad. En este sentido, Delgado (2013) nos hace ver que, en general, el artivismo lo que pretende es hacer reflexionar desde un enfoque creativo e inspirar a otros a unirse y participar de la acción; aunque el artivismo también es un movimiento que ha surgido de la clase media occidental con una premisa sobreprotectora y paternalista hacia quienes no siempre piden ser defendidos.

Aproximadamente en la década de 1960 surge el arte feminista hecho por mujeres y de temática política sobre el universo de la mujer, sus inquietudes y su participación en la sociedad. Como puntualiza Baldini (2017), es un arte realizado por y para mujeres occidentales, blancas, liberales, de clase media; un discurso hegemónico donde no se tiene en cuenta la problemática o la realidad opresiva de otras mujeres pertenecientes a esferas sociales más bajas o a otros grupos religiosos o étnicos. En cierta forma, se ha hecho patente la supremacía del feminismo occidental sobre el oriental y más tarde se ha ido tomando conciencia de cómo afecta, además, el racismo sobre las mujeres que lo padecen. Esto hizo que surgieran, por ejemplo, grupos feministas de mujeres de otras etnias, razas y religiones. Por tanto, este estudio pone en valor los Flashmobs realizados por mujeres orientales para averiguar si esta es una herramienta adecuada para el artivismo feminista.

En la actualidad, las religiones mayoritarias de la India y el sudeste asiático son el hinduismo, el islam y el budismo. En la India conviven hinduistas y musulmanes, siendo mayoría un $80 \%$ los primeros, al contrario que en Indonesia o Malasia, donde el porcentaje musulmán es mayor (Gil Pérez 2017). En Tailandia la religión preponderante es el budismo, aunque en el sur del país el islam tiene mayor número de adeptos por su proximidad fronteriza con Malasia (Sittichai \& Smith 2018).

La globalización ha hecho que el avance de la tecnología haya llegado a todos los puntos del planeta. Resulta normal ver a mujeres veladas caminando con sus smartphones por las calles, haciendo uso de las aplicaciones de la telefonía móvil no solo en occidente, sino también en cualquier país asiático. Dentro del ciberislam 
denominado por Enterría (2009), la comunidad musulmana utiliza Internet para practicar su credo y comprar artículos para seguir los preceptos de su religión. Fuera del ámbito del culto religioso, las mujeres hinduistas, musulmanas y budistas utilizan las redes sociales, las App e Internet para contactar entre ellas y darse a conocer fuera de su entorno más próximo.

Actualmente en Asia, lo cibercultural está muy presente en la sociedad y el artivismo que se lleva a cabo, cada vez con más presencia, «cobra fuerza y sirve para empoderar a la mujer artista. Performances, ilustraciones, caricaturas, instalaciones, canciones y hasta campañas de contra-publicidad conforman el artivismo feminista actual» (Maldonado 2019, 65). Precisamente fue el movimiento feminista quien se rebela contra el consumismo focalizado en la publicidad de productos para la mujer, como maquillaje, ropa, artefactos para la limpieza del hogar, no comprándolos (Douglas 1994).

La contra-publicidad o el culture jamming es una táctica contra el consumo descontrolado que fomenta el capitalismo. A través de la parodia se generan nuevos significados que buscan repensar el mensaje inicial: «El logro es valerse de los mismos códigos que conforman el discurso publicitario, hablar con el mismo lenguaje, utilizar el mismo horizonte de expectativas de la empresa para vomitar un mensaje revelador y contestatario» (González 2017, 58). Ejemplo de esto son las artistas Barbara Kruger, con la obra I shop therefore I $a m^{2}$, o la artista Jenny Holzer y su instalación en fachadas de edificios titulada Protect me from what I want ${ }^{3}$, donde ambas reflexionan sobre el consumismo y el ámbito público (Muñoz-Muñoz y Barbaño 2014). Esta tipología artística y reivindicativa ya ha tomado su espacio en el mundo oriental. De hecho, el diario The Indian Express (2017) publicó la noticia de un grupo de chicas estudiantes de la universidad de Kerala que habían sido insultadas y trolleadas en las redes sociales por tomar parte en una flashmob que alertaba del peligro del SIDA, utilizando el hiyab

Por todo ello, el principal objetivo de estudio de este trabajo es analizar al Flashmob como forma de expresión corporal en las redes sociales y valorar qué repercusión puede tener dentro del movimiento artivista y del feminismo en países asiáticos. Ante la voluminosa información que existe sobre estos movimientos en occidente, se considera necesario el intentar llegar a conocer la realidad de las mujeres orientales y su implicación como internautas en relación a sus derechos y libertades establecidas en los roles de género a través de estos géneros de comunicación.

Véase https: / / www.moma.org/ collection/works / 64897

Véase https: / / www.tate.org.uk/art/artists/jenny-holzer-1307/5-ways-jenny-holzer-brought-art«Flash mob in Kerala protests "insult to students in hijab"», Indian Express, 10 de diciembre de 2017. Disponible en https: / / indianexpress.com/article/india/kerala-flash-mob-protests-insultto-students-in-hijab-4975917/ 


\section{Metodología}

El objeto de estudio son videos de la red social Instagram subidos en un período de tiempo comprendido entre agosto y noviembre de 2019. Los audiovisuales propuestos como objeto de estudio han sido seleccionados por medio de palabras clave o etiquetas, utilizando el hashtag \#instaflashmob, ya que en Instagram el hashtag \#flashmob por sí mismo o acompañado de la etiqueta de una nacionalidad concreta no producía resultados de búsqueda. Puntualizar que con el hashtag \# danceflashmob también es posible encontrar resultados, aunque solo existen 5.000 publicaciones frente a los $47.2 \mathrm{k}$ publicaciones del primero.

No se ha ampliado el estudio a otras webs como YouTube por la falta de datos contenidos. Según Pérez-Rufi $(2012,50)$, «desde que Google adquirió YouTube dejaron de ser públicos los datos estadísticos acerca del volumen de visionados, tráfico de datos, número de usuarios», lo que impide en la actualidad conocer el cómputo global de vídeos que cumplan las características exigidas.

Dado que no existen casi estudios que reflejen la participación de la mujer asiática en el Flashmob, se ha considerado como más adecuada la metodología basada en un análisis cuantitativo y descriptivo de contenido mediante la recopilación de información a través de imágenes, permitiendo observar de modo exhaustivo las distintas variables del tipo naturaleza geográfica, vídeos en los que sólo aparecen mujeres, conjuntos integrados por hombres y mujeres, diferentes espacios donde se graban las imágenes, la tipología musical y el tipo de vestimenta, como se muestra en la Tabla 1.

\section{Datos}

Tras la búsqueda se identificaron en Instagram 26.387 publicaciones, de las cuales se han elegido cronológicamente 300 vídeos por su pertenencia exclusiva a países asiáticos.

Tabla 1

Relación numérica y de porcentajes de vídeos analizados con la temática Flashmob

\begin{tabular}{|c|c|c|c|c|c|c|c|c|c|}
\hline Países & 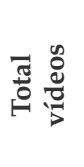 & 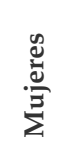 & 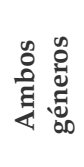 & 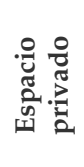 & 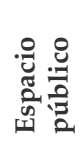 & 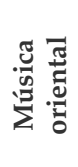 & 宽 & 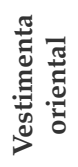 & 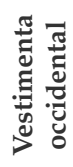 \\
\hline India & 150 & $\begin{array}{c}33 \\
22 \%\end{array}$ & $\begin{array}{c}117 \\
78 \%\end{array}$ & $\begin{array}{c}23 \\
15 \%\end{array}$ & $\begin{array}{c}127 \\
85 \%\end{array}$ & $\begin{array}{c}89 \\
59 \%\end{array}$ & $\begin{array}{c}61 \\
41 \%\end{array}$ & $\begin{array}{r}128 \\
85 \%\end{array}$ & $\begin{array}{c}22 \\
15 \%\end{array}$ \\
\hline
\end{tabular}

(continua na página seguinte) 


\begin{tabular}{|c|c|c|c|c|c|c|c|c|c|}
\hline Países & 宽造 & 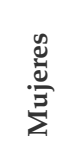 & 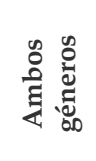 & 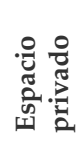 & 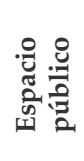 & 苞 & 苞 & 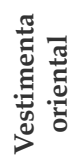 & 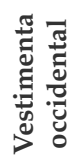 \\
\hline Indonesia & 103 & $\begin{array}{r}62 \\
60 \%\end{array}$ & $\begin{array}{c}41 \\
40 \% \%\end{array}$ & $\begin{array}{c}2 \\
2 \%\end{array}$ & $\begin{array}{l}101 \\
98 \%\end{array}$ & $\begin{array}{c}73 \\
71 \%\end{array}$ & $\begin{array}{c}30 \\
29 \%\end{array}$ & $\begin{array}{c}75 \\
72 \%\end{array}$ & $\begin{array}{c}28 \\
28 \%\end{array}$ \\
\hline Malasia & 29 & $\begin{array}{c}11 \\
38 \%\end{array}$ & $\begin{array}{r}18 \\
62 \%\end{array}$ & $\begin{array}{c}4 \\
14 \%\end{array}$ & $\begin{array}{c}25 \\
86 \%\end{array}$ & $\begin{array}{c}12 \\
41 \%\end{array}$ & $\begin{array}{c}17 \\
59 \%\end{array}$ & $\begin{array}{c}22 \\
75 \%\end{array}$ & $\begin{array}{c}7 \\
25 \%\end{array}$ \\
\hline Tailandia & 18 & $\begin{array}{r}12 \\
67 \%\end{array}$ & $\begin{array}{c}6 \\
33 \%\end{array}$ & $\begin{array}{c}0 \\
0 \%\end{array}$ & $\begin{array}{c}18 \\
100 \%\end{array}$ & $\begin{array}{c}2 \\
11 \%\end{array}$ & $\begin{array}{c}16 \\
89 \%\end{array}$ & $\begin{array}{l}3 \\
17\end{array}$ & $\begin{array}{c}15 \\
83 \%\end{array}$ \\
\hline Total & 300 & $\begin{array}{l}118 \\
39 \%\end{array}$ & $\begin{array}{l}182 \\
61 \%\end{array}$ & $\begin{array}{c}29 \\
10 \%\end{array}$ & $\begin{array}{l}271 \\
90 \%\end{array}$ & $\begin{array}{l}176 \\
59 \%\end{array}$ & $\begin{array}{l}124 \\
41 \%\end{array}$ & $\begin{array}{l}228 \\
76 \%\end{array}$ & $\begin{array}{c}72 \\
24 \%\end{array}$ \\
\hline
\end{tabular}

Fuente: Elaboración propia.

En términos globales son numerosas las propuestas en las que aparecen hombres y mujeres de forma conjunta $(61 \%)$ realizando propuestas de intervención, en contraste con las apariciones en las que solamente aparecen mujeres (39\%). Estos datos vienen a significar que la participación de las mujeres en grupos autónomos sin intervención masculina es mayoritaria en Indonesia (60\%) y Tailandia (67\%), y la participación más baja sucede en India, con tan solo un 22\% de la muestra seleccionada. Por tanto, la mujer india tiene menor autonomía que la tailandesa en cuanto a la gestión participativa en el espacio público. Únicamente un sector reducido de las mujeres indias tiene mayores privilegios que la mayoría (Gangoli 2016) debido al sistema de castas que no existe en Tailandia o en otros países asiáticos.

En lo referente a los espacios en donde tienen lugar las incursiones de los Flashmobs, se ha definido como espacios públicos calles, plazas, jardines, centros comerciales y oficinas, siendo estos los más utilizados (90\%) frente al espacio privado como el propio hogar (10\%). En otro sentido, también se ha podido observar, sobre todo en la India, que muchas de las coreografías han sido realizadas para festejar algún tipo de celebración como bodas, cumpleaños o festividades similares.

En cuanto a la utilización de la música que se escucha mientras tiene lugar el Flashmob, es notoria la presencia de música occidental (41\%) incluyendo temas de máxima actualidad a nivel internacional de intérpretes estadounidenses como Shakira o Justin Bieber, por citar a algunos. Aunque la música oriental tiene un porcentaje más alto (59\%), sobre todo en países como India e Indonesia, al contrario que en Malasia y Tailandia, donde ocupa un porcentaje relativamente más bajo. En las coreografías de India particularmente e Indonesia, está muy presente el influjo que tiene el cine de Bollywood con su particular riqueza musical que abarca desde canciones tradicionales a sonidos relacionados con la música más pop. 
Otro aspecto a tener en cuenta en las propuestas analizadas es el uso de la vestimenta. Del total de la muestra, es destacable la presencia de mujeres ataviadas con elementos característicos de su cultura. El sari, el salwar y el kurti es utilizado por el $85 \%$ de las mujeres de la India frente a un 15\% que vestía de forma occidental. Se puede precisar la existencia de mujeres bailando con velo y kebaya en países de creencias islamistas como Malasia e Indonesia, con un total del 75\% y $72 \%$ respectivamente. Solo en Tailandia el $83 \%$ no utiliza velo ni ropa tradicional típica de su cultura, sino que su vestimenta es de tipo occidental. De ahí que, en el total de las representaciones visuales en las que puede verse a mujeres bailando, un $76 \%$ se decanta por una indumentaria oriental. Sin embargo, contrasta notoriamente que, frente a los porcentajes establecidos en las mujeres, el $82 \%$ de los hombres que aparecen en los vídeos vestían con ropa occidental.

Figura 1

Cómputo total de las variables observadas

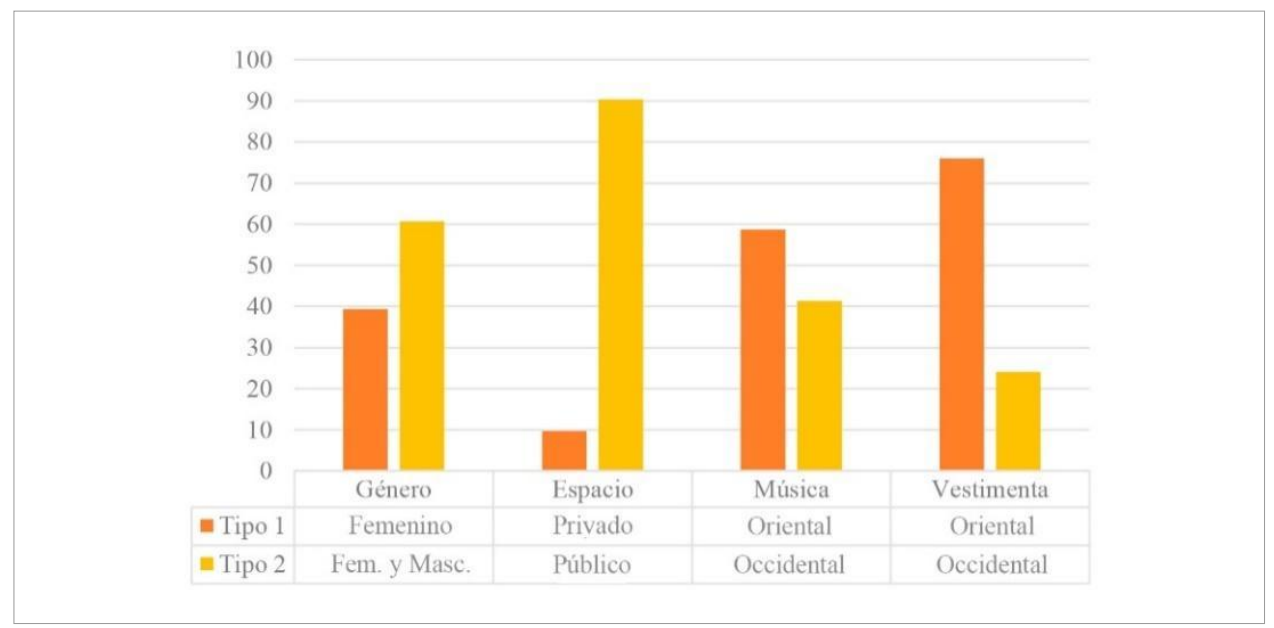

Fuente: Elaboración propia.

\section{Discusión y conclusiones}

En el presente estudio se ha detectado, al introducir el vocablo Flashmob en la red social Instagram, la existencia de numerosos vídeos subidos por mujeres hindúes, musulmanas y budistas, sobre todo de India, Indonesia, Malasia y Tailandia. Hay que tener en cuenta que países como China y otros de medio oriente tienen restringido el acceso a webs como Google, Facebook, Twitter, YouTube, Wikipedia o Instagram (Miller 2018). En ellos se observa cómo estas mujeres bailan y realizan coreografías musicales mayormente en espacios públicos como centros comercia- 
les, calles, plazas o parques, emulando las coreografías y los Flashmob que se realizan en occidente, sin que pueda apreciarse en ello signo alguno de vulnerabilidad o pudor ante la forma de hacerse presente en los espacios públicos señalados.

Para Chhachhi (1989), el surgimiento en Asia del fundamentalismo religioso junto a la falta de desarrollo industrial y de democracias reales ha ralentizado el empoderamiento de la mujer en la India y en el sudeste asiático, y las enclaustra en castas, en donde resulta casi imposible dejar que la mujer se manifieste de manera libre y realista con la situación y el momento que vive. Diversos movimientos sociales han protestado y han logrado que los gobiernos legislen para cuidar de las mujeres, pero todavía éstas son sometidas a agresiones físicas tanto en el propio hogar como en la calle, vulnerando todos los derechos que tienen como personas. Por todo esto, en los países musulmanes durante las últimas décadas ha ido creciendo entre algunos colectivos femeninos un espíritu revolucionario de lucha por garantizar los derechos de las mujeres y su acceso a disfrutar de la vida pública en igualdad con los varones (Carvalho-Pinto \& Fleschenberg 2019).

En India, por ejemplo, no existe la obligación explicita de cubrirse la cabeza con un velo, pero sí está arraigado como prenda femenina, y no está bien visto por los sectores más conservadores que una mujer acceda sola a espacios públicos si no es en compañía de un hombre (Sharma 1978). En muchos puntos de la geografía asiática, la ideología reaccionaria hace un llamamiento para que las mujeres usen el velo si salen de casa por motivos laborales o si quieren acceder a los espacios públicos en nombre de tradiciones ancestrales. La forma en la que éstas mujeres visten es un fiel reflejo que queda presente en muchos de los vídeos analizados. Sin embargo, es común observar a los hombres de estos mismos países usando ropa occidental sin que les resulte tan importante la tradición o la cultura por la que las mujeres deben de llevar dichas prendas de vestir alejándose por completo de la vestimenta occidental. Para ellos no existe la imperiosa obligación de vestir con sus prendas tradicionales. Por tanto, la mujer es víctima por el hecho de haber nacido mujer y sus derechos son mermados y dirigidos por el patriarcado imperante. Su visibilidad en los espacios públicos debe pasar lo más inadvertida posible, ya que «las mujeres no tienen valor sin sus velos; ponerse el velo es la única forma en que las mujeres pueden alcanzar valores sociales y morales» (Tami 2017, 137).

El reflejo que las redes sociales permite mostrar a través de las distintas manifestaciones del arte pone en evidencia que «el feminismo musulmán se erige sobre el espíritu igualitario del islam oponiéndose a las lecturas, interpretaciones y manipulaciones patriarcales del Libro Sagrado» (Valcárcel \& Sánchez 2014, 59), postulándose por la necesidad de querer pertenecer a una vida más igualitaria y visible ante el mundo, en donde la comunicación y el uso de los lenguajes comunicativos artísticos no puede quedar estancado y mucho menos aislado (DunbarHester 2009). Es decir, ver a las mujeres musulmanas realizando flashmobs ataviadas con velo no invalida la reivindicación feminista. 
En otro estudio, Meso Ayerdi (2004) advierte que el uso de las redes sociales e Internet para conectar individuos y para que estos realicen una actividad conjunta en los espacios públicos es una forma novedosa de fomentar la comunicación humana. Con ello, no se debe descuidar que el objetivo del artivismo ha de contener una intención, un mensaje o una propuesta clara, ya sea de índole artística, social o política. Por tanto, un Flashmob artivista ha de ser enriquecido dotándolo de concepto, para que las acciones no generen contenidos carentes de sentido y que a largo plazo sean más que eventualidades. Por tanto, al artivista occidental, el uso del Flashmob en países subdesarrollados le puede parecer, desde la óptica supremacista, bastante naíf y carente de una carga artística o ideológica sustancial porque el análisis de contenido presenta en algunas ocasiones la carencia de un propósito concreto y reivindicativo por y para las mujeres. Sin embargo, esto es una visión equivocada, ya que el Flashmob es una herramienta que fortalece el discurso corporal femenino porque la acción gestual es el medio de comunicación más vital que el ser humano conoce.

El apelativo del Flashmob en los videos visionados es utilizado con la única finalidad de subir a las redes sociales un vídeo con una coreografía. Hecho que podría catalogarse de inocente, meramente festivo o lúdico, sin el componente social o político que a simple vista parece requerir el artivismo feminista. Y es cierto, aunque en algunos casos pueda darse de forma desvirtuada sin el componente estrictamente social o político que requiere el artivismo más purista, al menos, está logrando que las mujeres tomen los espacios públicos para hacerse visibles, divertirse y, sobre todo, enviar esa información al exterior. Como destaca Díaz Gandasegui (2011), el gran logro de las redes sociales es la capacidad de generar una comunidad y traspasar las fronteras de lo físico con el fin de lanzar mensajes claros y comprensibles que surtan efecto en el receptor. Solo de esta forma puede llegar a conformarse una comunidad virtual y un intercambio de información complementaria que otorga poder a quien lo usa (Rheingold 2003).

Por otra parte, no debemos olvidar que el artivismo puede ser considerado como la ornamentación estética de una ideología, que de algún modo deja implícito un mensaje con un alto contenido reivindicativo. En Asia ya ha empezado a producirse un pequeño paso, en donde las mujeres pueden salir a la calle a bailar y grabar sus coreografías para posteriormente subirlas a la red y dejarlas en el espacio virtual como una bandera. Esta acción, que puede parecer una pequeña revolución inocente, es una gran intervención que va dejando huella y constituyendo un hito: el de que estas mujeres se sientan orgullosas de mostrar sus cuerpos bailando y contoneándose en espacios públicos, los espacios que por derecho han de pertenecer en igualdad a las personas y no únicamente a los hombres. Hacer una revolución no siempre ha de ser por la fuerza y por la línea más dura o radical, precisamente la descolonización de la India liderada por Gandhi es un claro ejemplo de lo contrario. Por ello, es necesario considerar que las mujeres asiáticas han comenzado, aunque a la sociedad occidental le pueda parecer inge- 
nuo o desvirtuado, una forma no formalmente artivista, pero sí de empoderamiento y expresión más allá de la palabra, de manifiestos y textos, basada en el gesto, la danza y el movimiento corporal. Al fin y al cabo, las acciones tienen más fuerza que las palabras.

\section{Referencias}

Álvarez, Lucía. 2018. «Uno, dos, tres... muchos 68: Hacia una memoria descentrada del mayo francés.» Nueva Sociedad 276: 172-180. Disponible en https://nuso.org/articulo/ uno-dos-tres-muchos-68 / [Consultado 16 de agosto de 2020].

Artaud, Antonin. 1996. El teatro y su doble. Barcelona: Pocket Edhasa.

Baldini, Vanessa. 2017. Articulate: Feminist Text-Art from the 1990s-Today: Four Case Studies. New York: ProQuest Dissertations Publishing.

Beuys, Joseph. 1983. «Jeder Mensch ist ein Künstler.» Praktische Theologie 18: 5-12. DOI: https: / / doi.org/10.14315/prth-1983-3-403

Boal, Augusto. 1989. Teatro del oprimido 1. Mexico: Nueva Imagen.

Brook, Peter. 1987. El espacio vacío. La Habana, Cuba: Editorial Pueblo y Educación.

Carvalho-Pinto, Vânia, y Andrea Fleschenberg. 2019. "As múltiplas inter-relações entre questões de género e a aquisição de status na arena internacional.» ex aequo 40: 9-14. DOI: https: / / doi.org/10.22355/ exaequo.2019.40.01

Chauca, Pilar. 2012. «El Flashmob: antecedentes y perspectivas como práctica escénica comprometida sociopolíticamente.» ASRI: Arte y sociedad. Revista de investigación 1. Disponible en https: / / www.eumed.net/rev/ays / 1/pc.html [Consultado 02 de julio de 2020].

Chauca, Pilar. 2015. «El Flashmob, respuestas artísticas hoy.» Revista de Estudios Globales y Arte Contemporáneo 3(1): 322-337. DOI: https: / / doi.org/10.1344 / regac2015.1.13

Chesney-Lawrence, Luis. 2013. «Las teorías dramáticas de Augusto Boal.» Teatro: Revista de Estudios Culturales/A Journal of Cultural Studies 26: 24-55. Disponible en https: / / digitalcommons.conncoll.edu/teatro/vol26/iss26/2/ [Consultado 19 de agosto de 2020].

Chhachhi, Amrita. 1989. «The State, Religious Fundamentalism and Women: Trends in South Asia.» Economic and Political Weekly 24: 567-578.

Chomsky, Noam. 1997. Media Control. The Spectacular Achievements of Propaganda. The Open Media Pamphlet Series. New York: Seven Stories Press.

Delgado, Manuel. 2013. «Artivismo y pospolítica. Sobre la estetización de las luchas sociales en contextos urbanos.» Quaderns-e de l'Institut Català d'Antropologia 18(2): 68-80. Disponible en https://www.raco.cat/index.php/QuadernseICA/article/view/274290 [Consultado 11 de julio de 2020].

Díaz Gandasegui, Vicente. 2011. «Mitos y realidades de las redes sociales. Información y comunicación en la Sociedad de la Información.» Prisma Social 6: 1-26. Disponible en https: / / www.isdfundacion.org / publicaciones / revista / numeros / 6/ secciones / tematica / 07-mitos-realidades-redes-sociales.html [Consultado 06 de mayo de 2020].

Dinucci, Darcy. 1999. «Fragmented Future.» PRINT Magazine. Disponible en http:/ / darcyd. com/fragmented_future.pdf [Consultado 24 de agosto de 2019].

Douglas, Susan. 1994. Where the Girls Are: Growing up Female with the Mass Media. New York: Times Book.

Dunbar-Hester, Christina. 2009. «"Free the spectrum!" Activist encounters with old and new media technology.» New Media \& Society 11(1-2): 221-240. DOI: https: / / doi.org/10.11 $77 / 1461444808100160$ 
Enterría, Arturo. 2009. «El Islam en Internet: El concepto de ciberislam.» Revista de Estudios Internacionales Mediterráneos 8: 1-10. Disponible en https://revistas.uam.es/reim/ article/view / 819 [Consultado 04 de julio de 2020].

Fernández-Quesada, Blanca. 2000. «Nuevos lugares de intención: intervenciones artísticas en el espacio urbano como una de las salidas a los circuitos convencionales: Estados Unidos 1965-1995.» Tesis doctoral, Universidad Complutense de Madrid.

Gangoli, Geetanjali. 2016. Indian Feminisms: Law, Patriarchies and Violence in India. New York: Routledge.

Gil Pérez, Javier. 2017. «La India, a setenta años de la independencia.» Razón y fe 276(1427): 137-147. Disponible en https:/ / revistas.comillas.edu/index.php/razonyfe/article/ view / 9315 [Consultado 09 de junio de 2020].

González Marí, Ximo. 2017. «Contrapublicidad en la ciudad del consumo. Subvirtiendo el sentido en la piel del asfalto.» Kult-ur 4(8): 43-72. DOI: https: / / doi.org/10.6035/Kultur.2017.4.8.1

Gordimer, Nadine. 1984. »The Essential Gesture: Writers and Responsibility.» The Tanner Lectures on Human Values, Delivered at the University of Michigan. Disponible en https:/ / tannerlectures.utah.edu/_resources/documents/a-to-z/g/gordimer85.pdf [Consultado 21 de octubre de 2019].

Gore, Georgiana. 2010. «Flash Mob Dance and the Territorialisation of Urban Movement.» Anthropological Notebooks 16(3): 125-131. Disponible en http: / / www.drustvo-antropologov.si / AN/PDF / 2010_3/Anthropological_Notebooks_XVI_3_Gore.pdf [Consultado 12 de agosto de 2020].

Korobina, Irina. 2015. «Building a New World. The Soviet Architectural Avant-Garde.» Texts 3: 83-94. Disponible en https:/ / art-texts.com/wp-content/uploads / 2019/10/2015_3_ web-1.pdf\#page=83 [Consultado 06 de mayo de 2020].

Maldonado, María Rosario. 2019. «Artivismo para combatir la injusticia social. El trinomio arte-activismo-comunicación se convierte en aliado del feminismo.» Aularia: Revista Digital de Comunicación 8: 65-72. Disponible en https://www.aularia.org/lib/pdf/ Aularia_15.pdf [Consultado 22 de mayo de 2020].

Marcillas Piquer, Isabel. 2013. «Flashmobs: la transformación de la dramaturgia a través de las redes sociales.» En Teatro e Internet en la primera década del siglo XXI, editado por José Romera Castillo, 235-249. Madrid: Editorial Verbum.

Meso Ayerdi, Koldobika. 2004. «Teléfonos móviles e Internet, nuevas tecnologías para construir un espacio público contrainformativo. El ejemplo de los flash mob en la tarde del 13M.» Revista Latina de Comunicación Social 7: 1-6. Disponible en http: / / www.revistalatinacs.org/20041558meso.htm [Consultado 10 de junio de 2020].

Miller, María Emilia. 2018. «Acceso en Internet y libertad de expresión en línea: ¿Derechos humanos?» Revista de Derecho Público 53: 77-83. DOI: https:/ / doi.org/10.31672/53.5

Molnár, Virág. 2014. «Reframing Public Space Through Digital Mobilization: Flash Mobs and Contemporary Urban Youth Culture.» Space and Culture 17(1): 43-58. DOI: https:/ / doi.org/10.1177/1206331212452368

Muñoz - Muñoz, Ana, y María Barbaño González-Moreno. 2014. «La mujer como objeto (modelo) y sujeto (fotógrafa) en la fotografía.» Arte, Individuo y Sociedad 26(1): 39-54. DOI: https:/ / doi.org/10.5209/rev_ARIS.2014.v26.n1.40581

Pavis, Patrice. 2008. «Puesta en escena, performance: ¿cuál es la diferencia?» Telondefondo: Revista de Teoría y Crítica Teatral 7: 1-37.

Pérez Rufi, José Patricio. 2012. «La actualidad en YouTube: claves de los videos más vistos durante un mes.» Global Media Journal 9(17): 44-62. Disponible en https:/ /www. redalyc.org/articulo.oa?id=68723565004 [Consultado 15 de abril de 2020]. 
Prowse, Peter, Ana Lopes, \& Ray Fells. 2017. «Community and union-led living wage campaigns.» Employee Relations 39(6): 825-839. DOI: https: / / doi.org/10.1108 / ER-03-20170053

Ramonet, Ignacio. 2004.«Información, comunicación y globalización. El quinto poder.» Chasqui. Revista Latinoamericana de Comunicación 88: 26-31.

Rheingold, Howard. 2003. «Smart mobs. Les communautés intelligentes mobiles comment reconnaître le futur quand il vous tombe dessus?» Sociétés 1(79): 75-87. DOI: https: / / doi.org/10.3917/ soc.079.0075

Salaün, Serge. 2001. «La sociabilidad en el teatro (1890-1915).» Historia Social 41: 127-146. Disponible en http:/ / www.jstor.org/stable/40340789

Sartoretti, Irene. 2014. «Arte e ambiente: l'esperienza della land art.» Micron 27: 24-29. Disponible en https:/ / www.arpa.umbria.it/ resources/docs/micron \%2027/ micron-2724.pdf [Consultado 06 de mayo de 2020].

Sharma, Ursula. 1978. «Women and Their Affines: The Veil as a Symbol of Separation.» Man 13(2): 218-233. DOI: https: / / doi.org/10.2307/2800246

Sittichai, Ruthaychonnee, \& Peter K Smith. 2018. «Bullying and Cyberbullying in Thailand: Coping Strategies and Relation to Age, Gender, Religion and Victim Status.» NAER: Journal of New Approaches in Educational Research 7(1): 24-30. DOI: https://doi. org / 10.7821/naer.2018.1.254

Tami, Rosmah. 2017. «The Representation of the Islamic Veil in indonesian Contemporary Art: A Feminist Poststructuralist Approach.» English and Literature Journal 1(1): 126-145. Disponible en https: / / core.ac.uk/download/pdf/234749953.pdf [Consultado 23 de abril de 2020].

Tang, Xiaobing. 2016. «Street Theater and Subject Formation in Wartime China: Toward a New Form of Public Art.» Cross-Currents: East Asian History and Culture Review 5(1): 85-114. DOI: https:/ / doi.org/10.1353/ach.2016.0004

Torrents, Carlota, y Marta Castañer. 2009. «Las consignas en la expresión corporal: una puerta abierta para la creatividad y la creación coreográfica.» Tándem. Didáctica de la Educación Física 30: 111-121. Disponible en http: / / www.observesport.com/desktop/ images / docu / xri108fq.pdf [Consultado 29 de junio de 2020].

Valcárcel, Mayra Soledad, y Nazareth Sánchez. 2014. «Católicas y musulmanas: Negociando identidades y desafiando hegemonías desde los márgenes del feminismo.» Gênero E Direito. Periódico do Núcleo de Estudos e Pesquisas sobre Gênero e Direito 2: 120-147. Disponible en https://periodicos.ufpb.br/index.php/ged/article/view/20495/11691 [Consultado 03 de julio de 2020].

Teresa Colomina-Molina. Profesora asociada en el Departamento de Expresión Plástica, Musical y Dinámica de la Facultad de Educación de la Universidad de Murcia (España). Formó parte del Grupo de Investigación E0A6-07 Prácticas Artísticas Activas y Ciudadanía de la Facultad de Bellas Artes de la Universidad de Murcia.

Artículo recibido el 31 de enero y acceptado para su publicación el 31 de marzo de 2021. 